\title{
High-flow nasal oxygen
}

(a) CrossMark

\section{versus noninvasive ventilation in adult patients with cystic fibrosis: a randomized crossover physiological study}

Michael C. Sklar ${ }^{1,2}$, Martin Dres ${ }^{3,4}$, Nuttapol Rittayamai, ${ }^{3,5}$, Brent West ${ }^{6}$, Domenico Luca Grieco ${ }^{3,7}$, Irene Telias ${ }^{2,3}$, Detajin Junhasavasdikul ${ }^{3,8}$, Michela Rauseo ${ }^{2,9}$, Tai Pham², Fabiana Madotto ${ }^{10}$, Carolyn Campbell ${ }^{3}$,

Elizabeth Tullis ${ }^{6}$ and Laurent Brochard $2,3^{*}$

\begin{abstract}
Background: Noninvasive ventilation (NIV) is the first-line treatment of adult patients with exacerbations of cystic fibrosis (CF). High-flow nasal oxygen therapy (HFNT) might benefit patients with hypoxemia and can reduce physiological dead space. We hypothesized that HFNT and NIV would similarly reduce work of breathing and improving breathing pattern in CF patients. Our objective was to compare the effects of HFNT versus NIV in terms of work of breathing, assessed noninvasively by the thickening fraction of the diaphragm (TFdi, measured with ultrasound), breathing pattern, transcutaneous $\mathrm{CO}_{2}\left(\mathrm{PtCCO}_{2}\right)$, hemodynamics, dyspnea and comfort.
\end{abstract}

Methods: Adult CF patients who had been stabilized after requiring ventilatory support for a few days were enrolled and ventilated with HFNT and NIV for 30 min in crossover random order.

Results: Fifteen patients were enrolled. Compared to baseline, HFNT, but not NIV, reduced respiratory rate (by 3 breaths $/ \mathrm{min}, p=0.01$ ) and minute ventilation (by $2 \mathrm{~L} / \mathrm{min}, p=0.01$ ). Patients also took slightly larger tidal volumes with HFNT compared to NIV ( $p=0.02)$. TFdi per breath was similar under the two techniques and did not change from baseline. MAP increased from baseline with NIV and compared to HFNT $(p \leq 0.01)$. Comfort was poorer with the application of both HFNT and NIV than baseline. No differences were found for heart rate, $\mathrm{SpO}_{2}, \mathrm{PtcCO}_{2}$ or dyspnea.

Conclusions: In adult CF patients stabilized after indication for ventilatory support, HFNT and NIV have similar effects on diaphragmatic work per breath, but high-flow therapy confers additional physiological benefits by decreasing respiratory rate and minute ventilation.

Clinical trial registration: Ethics Committee of St. Michael's Hospital (REB \#14-338) and clinicaltrial.gov (NCT02262871).

\footnotetext{
*Correspondence: BrochardL@smh.ca

${ }^{3}$ Keenan Research Centre for Biomedical Science, Li Ka Shing Knowledge

Institute, St. Michael's Hopsital, 209 Victoria Street, 4th Floor, Room 411,

Toronto, ON M5B 1T8, Canada

Full list of author information is available at the end of the article
} 


\section{Background}

Cystic fibrosis (CF) is the most common autosomal recessive disorder in Caucasian populations [1]. Patients with CF experience exacerbations with hypercapnic respiratory failure associated with increased respiratory workload that may require intensive care unit (ICU) admission due to the inability of the respiratory muscles to compensate for an increased demand. Although no international recommendations currently exist [2], these exacerbations are frequently treated with noninvasive ventilation (NIV) $[2$, 3]. NIV has been shown to unload the respiratory muscles, increase alveolar ventilation and gas exchange [4] and reverse the rapid and shallow breathing pattern commonly adopted by CF patients with advanced lung disease [5].

NIV is a cornerstone therapy for hypercapnic acute respiratory failure [6, 7], but there is also an increasing interest in high-flow nasal therapy (HFNT) as a potential alternative treatment in this indication [8-10]. HFNT is a system delivering actively heated and fully humidified gas mixture with flow rates up to $60 \mathrm{~L} / \mathrm{min}$ and adjustable $\mathrm{FiO}_{2}$ from 21 to $100 \%$. The high flow rates generate small amounts of positive end-expiratory pressure (PEEP) that may help counterbalance the effects of intrinsic PEEP (PEEPi) on work of breathing and might act by washing out of the physiological dead space [11]. Furthermore, it could help to facilitate secretion clearance from the humidified gas [12].

Studies have demonstrated the benefits of HFNT in acute hypoxemic respiratory failure [13], after cardiothoracic surgery [14] and in the prevention of postextubation failure among unselected cohorts of critically ill patients during weaning from invasive mechanical ventilation $[15,16]$. However, the current evidence of using HFNT in patients with hypercapnic acute respiratory failure is limited $[9,10,17,18]$. CF is a unique respiratory disease with chronic, progressive, mixed obstructive-restrictive respiratory failure. From a physiological standpoint, this device could help CF patients with exacerbations in particular by improving gas exchange, reducing respiratory workload through reducing dead space, compensating for PEEPi and facilitating mucus clearance [19]. Additionally, a non-interrupted delivery of the technique with simple nasal prongs might improve comfort and tolerability compared to NIV via total face mask.

No study has compared the physiological effects of HFNT and NIV in adult CF patients requiring ventilator support. We hypothesized that HFNT and NIV would similarly reduce the work of breathing and improving breathing pattern in patients requiring ventilator support for CF exacerbations. Our objectives were to compare HFNT- and NIV-induced changes in inspiratory work of breathing assessed noninvasively by the thickening fraction of the diaphragm (TFdi) [20], breathing pattern, $\mathrm{CO}_{2}$ level, hemodynamics, dyspnea and comfort.

\section{Methods}

Detailed methods are available in Additional file 1.

\section{Study design}

Physiological prospective randomized crossover study (Fig. 1), using noninvasive assessments, was approved by the Ethics Committee of St. Michael's Hospital (REB \#14338) and registered on clinicaltrial.gov (NCT02262871). Patients provided their written informed consent. The study took place in a respiratory ward where NIV is usually delivered at St. Michael's Hospital, Toronto, from January 2015 to February 2017.

\section{Patients}

Hospitalized adult patients $>18$ years of age with CF were included in the study if they had a clinical indication for NIV at the time of admission based on at least one of the following criteria $[4,21]$ and had been stabilized with NIV as set by respiratory therapists, medically optimized with antibiotics and bronchodilators as necessary according to their treating physician before entering the study (in order to minimize the risk of abrupt decompensation):

- Signs of clinical respiratory distress: respiratory rate $>24 / \mathrm{min}$ or accessory muscle use

- Partial pressure of arterial carbon dioxide $\left(\mathrm{PaCO}_{2}\right)$ level $>45 \mathrm{mmHg}$ from the time of hospital admission

- Nocturnal hypoventilation treated by NIV but requiring daytime NIV because of clinical worsening defined as either of the two conditions above

- Diurnal hypercapnia $\left(\mathrm{PaCO}_{2}>45 \mathrm{mmHg}\right)$ or PtcCO2 $>40 \mathrm{mmHg}$ in patients who have persistent elevation of serum bicarbonate level $\left(\mathrm{HCO}_{3}{ }^{-} \geq 32 \mathrm{mmol} / \mathrm{L}\right)$.

\section{Experimental procedure and study design}

Enrolled patients received $30 \mathrm{~min}$ of HFNT or clinically set NIV in random order determined by a sealed opaque envelope. Physiological measurements were taken at baseline and at 25 min of each session of HFNT and NIV. Baseline oxygen settings were applied during a 10-minute washout period following the first device and at the end of the study.

HFNT (AIRVO-2 ${ }^{\circledR}$, Fisher \& Paykel, Auckland, New Zealand) was set to a maximal inspiratory flow rate of 55 $\mathrm{L} / \mathrm{min}$ as tolerated by the patient. $\mathrm{FiO}_{2}$ was adjusted to achieve a $\mathrm{SpO}_{2}$ of at least $92 \%$ and temperature at $37{ }^{\circ} \mathrm{C}$ or $34^{\circ} \mathrm{C}$ according to patient's individual preference.

Three NIV systems were used for the study depending on availability at enrollment (ResMed Stellar 150, ResMed VPAP III ST-A, ResMed Corp., California, USA or Respironics BiPAP Synchrony Respironics, Pennsylvania, USA). Two full face masks were available 


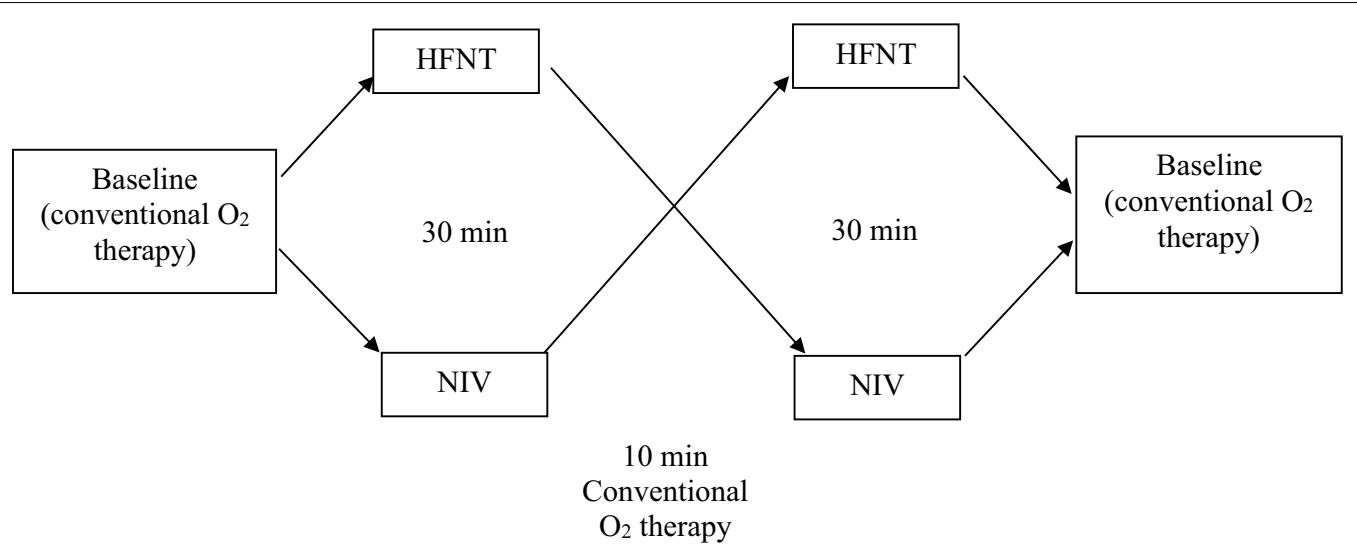

MEASUREMENTS

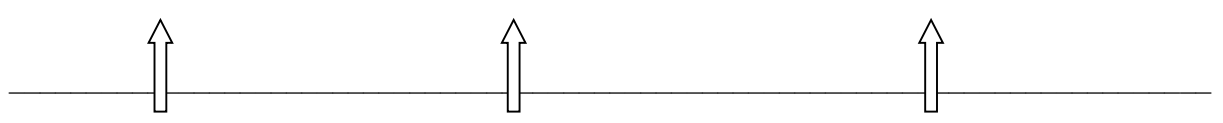

\begin{tabular}{|l|}
\hline -Diaphragm \\
thickening fraction \\
-Gas exchange \\
-Hemodynamics \\
-Dyspnea and \\
Comfort
\end{tabular}

$$
\begin{aligned}
& \text {-Diaphragm } \\
& \text { thickening fraction } \\
& \text {-Gas exchange } \\
& \text {-Hemodynamics } \\
& \text {-Dyspnea and } \\
& \text { Comfort }
\end{aligned}
$$

-Diaphragm
thickening fraction
-Gas exchange
-Hemodynamics
-Dyspnea and
Comfort

Fig. 1 Study design. Fifteen cystic fibrosis patients were oxygenated with high-flow nasal cannula and noninvasive ventilation for 30 min each in random order with a 10-min washout period after each device use. All measurements were taken at baseline and after 25 min on each device. HFNT high-flow nasal therapy, NIV noninvasive ventilation

and were chosen based on patient preference: ResMed Hospital Full Face Mask (California, USA) and Fisher \& Paykel Hospital Full Face Mask (Auckland, New Zealand). $\mathrm{FiO}_{2}$ was adjusted to achieve a $\mathrm{SpO}_{2}$ of at least $92 \%$. NIV settings were those previously adjusted by the respiratory therapy team, based on oxygenation, arterial blood gases and patient tolerance; they were not modified for the purpose of the study and were kept unaltered during the study period.

\section{Data collection}

Anthropometric data were obtained from the patient's medical chart including age, gender, height and weight, and the most recent pulmonary function testing and arterial blood gasses. In addition, patient baseline characteristics including significant comorbidities, admission diagnosis and severity of illness (APACHE II) scores were collected.

\section{Physiological measurements}

All patients were studied in the semi-recumbent position. Pulse oximetry and calibrated transcutaneous $\mathrm{CO}_{2}$ monitoring (SenTec Digital Monitoring System, Switzerland) were attached and monitored continuously during the study period [22]. A bio-impedance surface sensor (ExSpiron Monitor, Respiratory Motion, MA, USA) was placed and calibrated to measure noninvasively and continuously respiratory rate, tidal volume and minute ventilation [23].

A surrogate measure for work of breathing was estimated with diaphragm ultrasound as previously described [24, 25]. Diaphragm ultrasound examination was performed by a previously validated technique [26], using a SonoSite system (Fujifilm) equipped with a $13-\mathrm{MHz}$ ultrasound linear probe. Diaphragm thickening fraction (TFdi) was calculated offline using the $M$ mode $[$ TFdi $=($ thickness at end inspiration - thickness at end expiration)/thickness at end expiration] with reviewers blinded to the mode of support.

Dyspnea and comfort scores were measured from 0 to 10 on a visual analog scale as described previously [27] and validated in patients with chronic obstructive pulmonary disease (COPD) [28]. (Dyspnea: $0=$ no dyspnea, $10=$ maximal dyspnea. Comfort: $0=$ maximal discomfort, $10=$ very comfortable.) 


\section{Data management}

Demographics, physiological data and recordings data were recorded and de-identified for confidentiality.

\section{Statistical considerations}

At the time, this study was undertaken, there were no data on HFNT in hypercapnic patients, and nor was there robust physiological data on the use of NIV on adult patients with CF. In the absence of data allowing for an accurate estimation of sample size, we arbitrarily decided to enroll 15 patients in this exploratory study, with the hypothesis that this number would be sufficient to detect significant changes in respiratory effort.

Data are reported as median (interquartile range) for continuous variables and frequency (percentages) for categorical variables. The study is designed such that each participant is his/her own control. Differences between baseline conditions and each device as well as between devices differences were performed using the Wilcoxon signed-ranks paired test with a Bonferroni correction. Analyses were performed using Prism 4.01 software (GraphPad Software, San Diego, CA). For each comparison, a $p$ value $<0.05$ was considered significant.

\section{Results \\ Patients}

Fifteen adult patients with CF pulmonary exacerbations who had been stabilized over median 3 days under NIV and medical therapy were subsequently enrolled in the study (Additional file 1: Fig. 1). Patients were enrolled a median (interquartile range) of 5 (5-7) days after hospital admission. Characteristics of the subjects are detailed in Table 1. The NIV settings were those previously used by the clinicians and with which the patients had been stabilized. At baseline, all patients received oxygen via nasal prongs (range $0.5-10 \mathrm{~L} / \mathrm{min}$ ). All patients completed the study, and one patient did not have ultrasound measurements due to the unavailability of the machine at the time of data collection. In two patients, there were technical difficulties with the transcutaneous $\mathrm{CO}_{2}$ measurements. The ExSpiron monitor was not available in the early phase of the study and used for the latter 11 patients.

\section{Respiratory pattern at baseline}

The median (interquartile range) baseline oxygen flow rate was $3(2-5) \mathrm{L} / \mathrm{min}$. Patients had a respiratory rate of 21 (17-26) breaths per minute and $\mathrm{SpO}_{2}$ of 93 (90-94) \%. Dyspnea score was $1(0-3)$ and comfort score 9 (8-10), confirming the clinical stabilization. TFdi was 30 (24-45) $\%$.
Table 1 Patient characteristics

\begin{tabular}{|c|c|}
\hline Characteristics & $n=15$ \\
\hline Female, $n(\%)$ & $8(53)$ \\
\hline Age (years) & $30(23-34)$ \\
\hline Body mass index $\left(\mathrm{kg} / \mathrm{m}^{2}\right)$ & $19(17-22)$ \\
\hline APACHE II score at entry & $8(7-9.5)$ \\
\hline \multicolumn{2}{|l|}{ Baseline pulmonary function test } \\
\hline Forced expiratory volume in $1 \mathrm{~s}(\mathrm{~L})$ & $0.8(0.6-1.0)$ \\
\hline Forced expiratory volume in $1 \mathrm{~s}$ (\% predicted) & $24(20-26)$ \\
\hline Forced vital capacity (L) & $1.49(1.33-1.64)$ \\
\hline FEV1/FVC ratio (\%) & $45(42-52)$ \\
\hline \multicolumn{2}{|l|}{ Chronic comorbidities } \\
\hline Pancreatic insufficiency, $n(\%)$ & $11(73)$ \\
\hline Diabetes mellitus, $n$ (\%) & $5(33)$ \\
\hline Osteoporosis, $n(\%)$ & $4(27)$ \\
\hline \multicolumn{2}{|l|}{ Reason for admission } \\
\hline Cystic fibrosis exacerbation, $n(\%)$ & $15(100)$ \\
\hline \multicolumn{2}{|l|}{ Pulmonary therapy prior to admission } \\
\hline Supplemental oxygen as outpatient, $n$ (\%) & $12(80)$ \\
\hline Noninvasive ventilation as outpatient, $n(\%)$ & $9(60)$ \\
\hline Listed for lung transplantation, n (\%) & $10(67)$ \\
\hline \multicolumn{2}{|l|}{ Arterial blood gases ${ }^{a}$} \\
\hline $\mathrm{pH}$ & $7.39(7.38-7.41)$ \\
\hline $\mathrm{PaCO}_{2}(\mathrm{mmHg})$ & $53(49-63)$ \\
\hline $\mathrm{HCO}_{3}{ }^{-}(\mathrm{mmol} / \mathrm{L})$ & $34(31-38)$ \\
\hline $\mathrm{PaO}_{2}(\mathrm{mmHg})$ & $64(61-68)$ \\
\hline
\end{tabular}

Continuous variables are expressed as median (interquartile range), and categorical variables are expressed as absolute value (\%)

a For arterial blood gas conditions, please see Additional file 1:Table 1

\section{Effect of NIV and HFNT on respiratory pattern}

HFNT flow rate was $45(45-55) \mathrm{L} / \mathrm{min}$ with a $\mathrm{FiO}_{2}$ of 30 (25-35) \%. NIV was set at an inspiratory positive airway pressure of $14(12-18) \mathrm{cmH}_{2} \mathrm{O}$ and a positive expiratory airway pressure of $6(6-6) \mathrm{cmH}_{2} \mathrm{O}$. Flow rates, pressure settings and $\mathrm{FiO}_{2}$ were kept constant during the protocol. Individual device characteristics per patient are detailed in Additional file 1: Table 1.

No difference was observed in TFdi between baseline and either device (Table 2, Fig. 2). Compared to baseline, HFNT significantly reduced respiratory rate by a median (interquartile range) of $14 \%(8-37 \%)$, or 3 breaths $/ \mathrm{min}$, and minute ventilation by $27 \%$ ( -5 to $51 \%$ ), or $2 \mathrm{~L} / \mathrm{min}$, ( $p=0.01$ for both) (Table 2, Fig. 3). Compared to NIV, HFNT slightly increased VT by $10 \%(1.5-26 \%)(p=0.02)$ (Table 2, Fig. 3). For pulse oximetry and $\mathrm{PtcCO}_{2}$, there was no change between baseline conditions and either device or between devices (Table 2 and Fig. 3).

In a sensitivity analysis, we removed one outlying patient (\#14) with a large increase in TFdi with the application of NIV. This resulted in no changes to the statistical findings of our primary outcome of interest. 
Table 2 Changes in physiological variables induced by high-flow nasal cannula and noninvasive ventilation

\begin{tabular}{|c|c|c|c|c|c|c|}
\hline Variables & Baseline & NIV & HFNT & $\begin{array}{l}p \\
\text { Baseline } \\
\text { versus NIV }\end{array}$ & $\begin{array}{l}p \\
\text { Baseline } \\
\text { versus HFNT }\end{array}$ & $\begin{array}{l}p \\
\text { NIV } \\
\text { versus HFNT }\end{array}$ \\
\hline \multicolumn{7}{|l|}{ Respiratory pattern } \\
\hline Respiratory rate $\left(\mathrm{min}^{-1}\right)$ & $21(17-26)$ & $19(18-26)$ & $18(13-20)$ & 0.99 & 0.01 & 0.13 \\
\hline Tidal volume $(\mathrm{mL} / \mathrm{kg})$ & $5.4(4.3-10.6)$ & $5.6(3.9-10.6)$ & $5.6(4.2-10.2)$ & 0.49 & 0.49 & 0.02 \\
\hline Minute ventilation (L/min) & $6.9(5.3-11.5)$ & $5.6(5.0-8.4)$ & $5.0(4.2-6.6)$ & 0.46 & 0.01 & 0.46 \\
\hline $\mathrm{SpO}_{2}(\%)$ & $93(90-94)$ & $93(92-94)$ & $94(93-95)$ & 0.99 & 0.30 & 0.51 \\
\hline Transcutaneous $\mathrm{CO}_{2}(\mathrm{mmHg})$ & $53(42-60)$ & $53(41-60)$ & $54(41-60)$ & 0.99 & 0.98 & 0.99 \\
\hline \multicolumn{7}{|l|}{ Hemodynamic } \\
\hline Heart rate $\left(\mathrm{min}^{-1}\right)$ & $108(89-114)$ & $101(92-115)$ & $102(91-114)$ & 0.94 & 0.43 & 0.99 \\
\hline Mean arterial pressure $(\mathrm{mmHg})$ & $85(78-91)$ & $91(81-101)$ & $84(77-94)$ & $<0.01$ & 0.99 & 0.01 \\
\hline \multicolumn{7}{|l|}{ Diaphragm activity } \\
\hline Thickening fraction (\%) & $30(25-46)$ & $35(23-41)$ & $36(19-41)$ & 0.99 & 0.99 & 0.99 \\
\hline \multicolumn{7}{|l|}{ Symptoms } \\
\hline Dyspnea & $1(0-3)$ & $1(0-2)$ & $1(0-3)$ & 0.82 & 0.99 & 0.99 \\
\hline Comfort & $9(8-10)$ & $7(6-9)$ & $6(5-8)$ & 0.02 & $<0.01$ & 0.99 \\
\hline
\end{tabular}

Continuous variables are expressed as median (interquartile range). Devices are compared head to head, and each device is compared to baseline conditions using the Wilcoxon signed-ranks test.

HFNT high-flow nasal therapy, NIV noninvasive ventilation, $n=15$

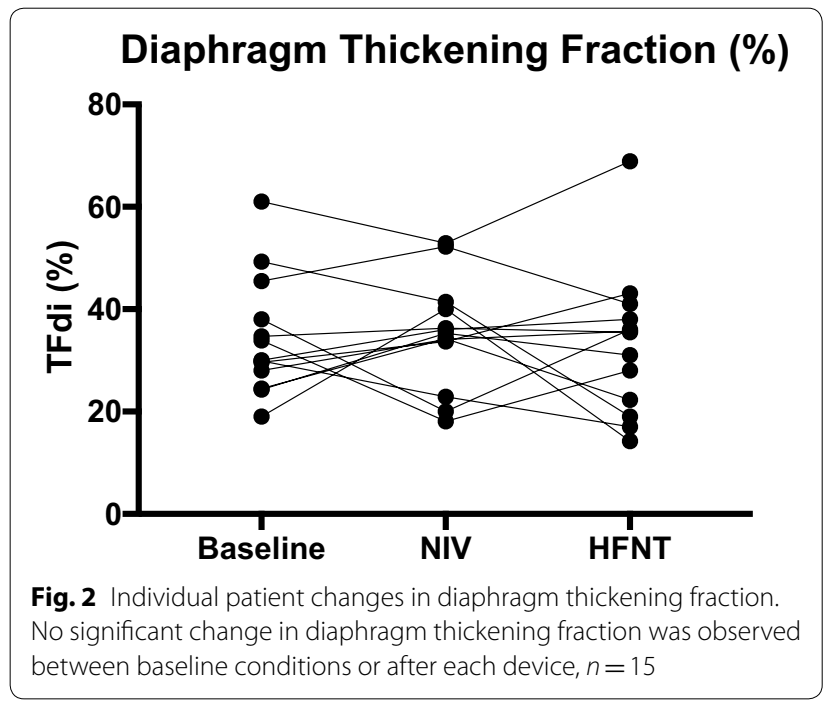

\section{Hemodynamics}

NIV slightly but significantly increased MAP compared to baseline and HFNT conditions $(p \leq 0.01$ for both) (Table 2). Heart rate remained unchanged across study conditions.

\section{Self-reported symptoms}

Dyspnea scores were low, and there was no difference between baseline and any condition (median visual analog scale score of 1 for all three devices). Compared to baseline, however, comfort scores were significantly reduced with the application of both NIV and HFNT $(9(8-10)$ vs $7(6-9)$ and $6(5-8)(p=0.02$ and $p<0.01$, respectively) (Table 2, Fig. 4). Thirteen out of the fifteen patients preferred one condition over the other, with 8 patients preferring NIV, while 5 had preference for HFNT.

\section{Discussion}

To our knowledge, this is the first physiological study that specifically investigates the role of HFNT in adult CF patients who may have unique physiological responses compared to other forms of chronic respiratory failure secondary to inspissated secretions, mixed pulmonary mechanics and potentially altered structure and function of the diaphragm. The main result of this study is that diaphragmatic activity per breath, as assessed by TFdi, is similar between HFNT and clinically set NIV session, but that HFNT is associated with reduction in respiratory rate and minute ventilation implying a further reduction in total diaphragmatic work per minute with this technique.

No difference was observed in TFdi between HFNT and NIV, supporting our hypothesis, but we were surprised that there was no measurable significant reduction from either device compared to the baseline TFdi. This finding held true after removing one patient with outlying values, further strengthening our confidence in these results.

We thought it was essential to have all assessments and measurements taken with noninvasive techniques 

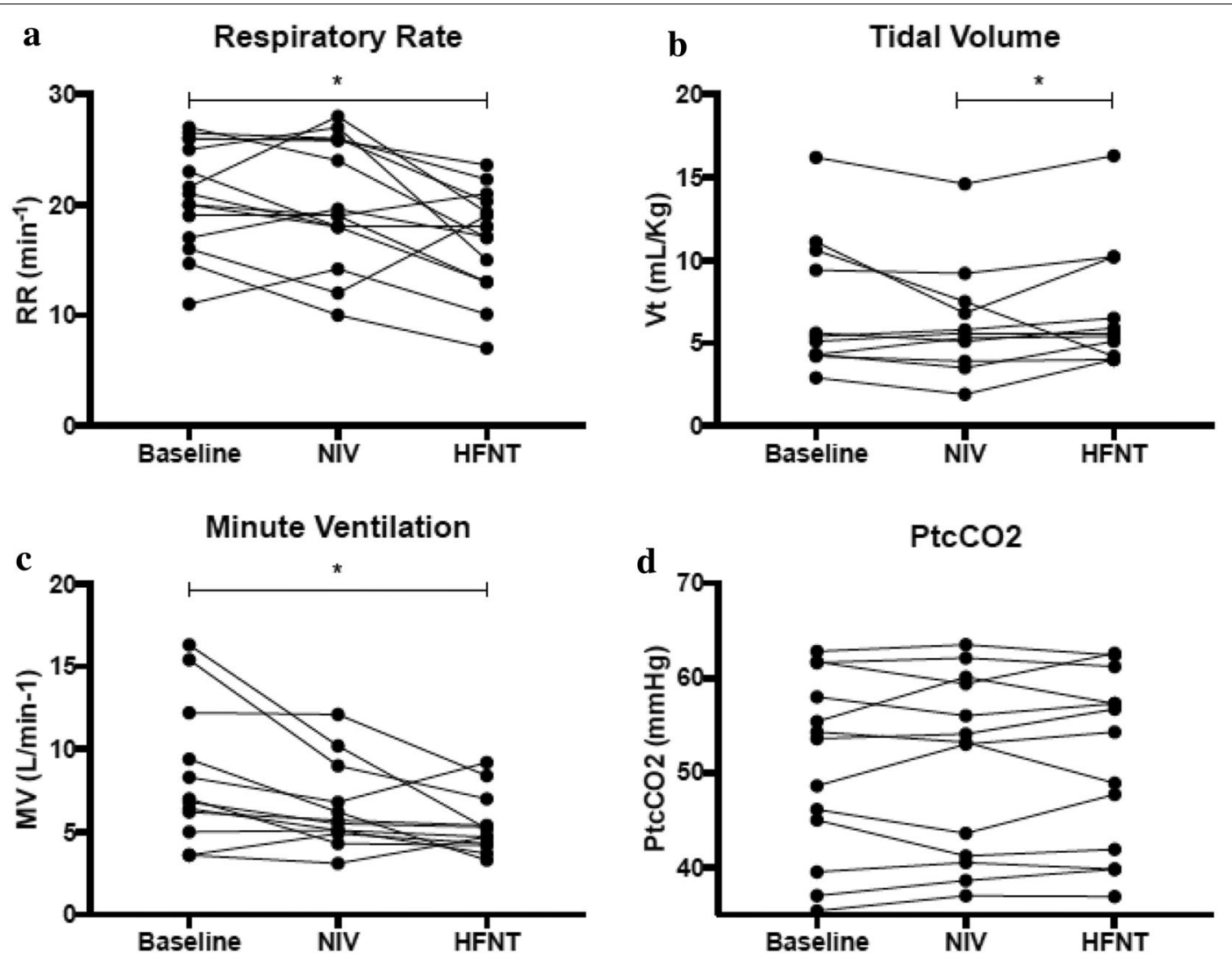

Fig. 3 Individual patient changes in respiratory variables. a HFNT significantly reduced respiratory rate compared to baseline and $\mathbf{b}$ significantly increased tidal volume when compared to NIV, c HFNT significantly reduced minute ventilation compared to baseline conditions, $\mathbf{d}$ no differences were observed for $\mathrm{PtcCO}_{2},{ }^{*} p<0.05$ (versus baseline). HFNT high-flow nasal therapy, NIV noninvasive ventilation, PtcCO, transcutaneous carbon dioxide, $n=15$

(e.g., external device for volume, ultrasonography for diaphragm activity, transcutaneous gas values) in order to minimize a direct effect of these techniques on the observed values (Heisenberg principle) [29, 30]. Importantly, however, these techniques are subject to measurement and performance error and we took great care to standardize the technical conditions for these measurements The lack of effect of diaphragmatic work might probably be explained by the relatively normalized (approximately 30\%) TFdi in these patients at baseline $[31,32]$ had been stabilized before protocol implementation. Despite having other clinical and biochemical indicators for ventilatory support, our subjects had improved and been stabilized prior to protocol initiation (all subjects weaned to nasal prong oxygen), making it difficult to demonstrate a difference in diaphragmatic work of breathing. This is in contrast to a report of 14 stable chronically hypercapnic COPD patients in which both HFNT and NIV significantly reduced PTPdi (diaphragmatic work) [8]. Furthermore, in a more recent study including 5 hypercapnic patients recovering from acute respiratory failure, esophageal pressure swings, PTP and work of breathing (markers of respiratory effort) were significantly reduced with HFNT at $60 \mathrm{~L} / \mathrm{min}$ [33]. This difference, however, may also stem from inherent differences in the structure and function of the diaphragm between COPD and CF patients [34].

It has been previously suggested that a concomitant metabolic alkalosis contributes to hypercapnic respiratory failure in exacerbations of adult $\mathrm{CF}$ and that these patients less frequently exhibit acidosis than COPD patients due to the abnormal electrolyte transport in $\mathrm{CF}$ patients compared to COPD, even during exacerbations $[35,36]$. This may have been present in our subjects as well with a median $\mathrm{pH}$ in the normal range NIV which has been clinically used for hypercapnic respiratory failure in CF, but little is known about its physiological effects, particularly in the adult population. A Cochrane review on NIV in 191 mixed adult and pediatric CF patients for several indications was limited by small sample sizes of adult-only trials, sparse reporting of physiological variables and heterogeneous inclusion of varying degrees disease severity [21]. 

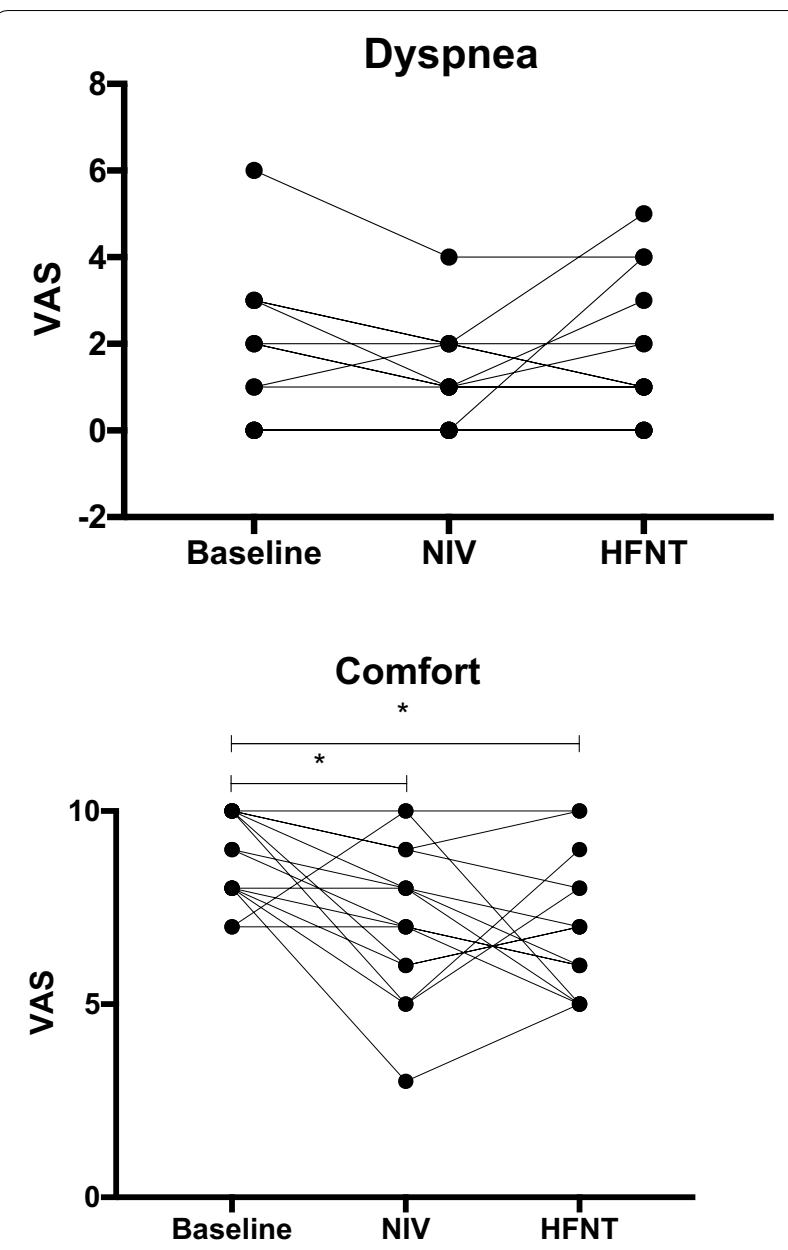

Fig. 4 Individual patient changes in symptom scores, $n=15$, with some symptom scores overlapping. a Dyspnea scores were unchanged between baseline conditions and the use of either HFNT or NIV. b Compared to baseline conditions, both NIV and HFNT reduced comfort scores, ${ }^{*} p<0.05$ (versus baseline), HFNT high-flow nasal therapy, NIV noninvasive ventilation. Dyspnea and comfort scores: (dyspnea: $0=$ no dyspnea, $10=$ maximal dyspnea. Comfort: $0=$ maximal discomfort, $10=$ very comfortable), $n=15$

Consistent with previous work, HFNT demonstrated a significant reduction in respiratory rate [37]. Despite a statistically significant, but likely clinically inconsequential small increase in Vt, there was an overall substantial decrease in MV, which has been previously reported in COPD patients treated with HFNT [17]. This finding is partly explained by HFNT washing out of anatomical dead space, allowing a larger fraction of the MV to participate in gas exchange, increasing the efficiency of the respiratory system and decreasing the work of breathing [12]. It might also be related to decreases in nasal inspiratory resistance [38], which may lead to reduced PEEPi and inspiratory load [39]. Importantly, the reduction in respiratory rate might turn into a parallel decrease in the energy expenditure of the respiratory muscles, here by approximately $15 \%$. Despite a significant reduction in minute ventilation, we found no concurrent reduction in $\mathrm{PtcCO}_{2}$, suggesting a reduced dead space and/or metabolic production. The significant reduction in respiratory rate and minute ventilation with HFNT suggests that the work of breathing per minute is substantially reduced, potentially between 15 and $25 \%$, correlating with a reduction in $\mathrm{CO}_{2}$ production by the respiratory muscles [40].

We found no significant improvement in dyspnea scores. Comfort scores were significantly lower with both devices compared to baseline oxygen. This finding might reflect relatively stabilized patients with high baseline comfort scores. Moreover, this finding may represent the response to a short-term effect and could differ with a more prolonged use, as suggested in the literature [18, 41]. Oddly, $60 \%$ of patients were prescribed NIV at home prior to hospitalization, yet had lower comfort scores compared to baseline. Patients were accustomed to this treatment, even if they did not find it comfortable. We suspect this is another sign that patients were not anymore in distress.

This short-term physiological study has limitations. Firstly, epressure support levels during NIV were lower than compared to one NIV study performed in young patients with CF (11-18 $\left.\mathrm{cmH}_{2} \mathrm{O}\right)$ [42]. These levels of pressure were not used clinically in our center, and this could have biased the results toward favoring a difference with HFNT. A recent Cochrane review, however, pointed out the paucity of studies in this situation to indicate optimal settings [21]. In addition, in a recent trial using NIV for physiotherapy, similar levels of pressure support $\left(8 \mathrm{cmH}_{2} \mathrm{O}\right)$ and PEEP $\left(5 \mathrm{cmH}_{2} \mathrm{O}\right)$ comparable to our study were used [43]. So, our data represent reasonable, although potentially not optimal, clinical settings. NIV was individually set according to clinical parameters and patient comfort by clinicians, allowing stabilization of the patients. This has probably resulted in normal levels of work of breathing. We are reassured that under NIV settings the TFdi was similar to values found in healthy volunteers [38]. Also, different NIV masks and NIV ventilators (based on resource availability) were used based on patient comfort. It is possible these different masks could perform differently with respect to the amount of leak, for example but the data obtained in other clinical settings do not suggest this has a great influence on work of breathing [44]. It is possible that, because $60 \%$ of our patients had used NIV at home, while none had used HFNT before, this could influence the physiological and subjective responses of our subjects.

Recent work suggests that physiological benefits of HFNT used in hypoxemic respiratory failure appear closely related to the applied flow rate [37]. Indeed, 
our median flow rate applied was $45(45-55) \mathrm{L} / \mathrm{min}$, and therefore, it is possible that further physiological improvement may have been seen if flow rates were maximized at $60 \mathrm{~L} / \mathrm{min}$. The level of flow rate, however, was dictated by patient's preference. In addition, a recent study showed that most of the effect on inspiratory workload and $\mathrm{CO}_{2}$ clearance is already obtained at the lowest flow rate [45]. In addition, it remains unclear whether the relationship between flow rate and physiological response holds true in chronically hypercapnic patients.

In contrast to previous physiological studies on HFNT $[8,33,37]$ that used esophageal balloon catheters, we chose to utilize diaphragm ultrasonography as our primary means of estimating patient work of breathing as previously demonstrated [24]. Although our approach makes direct comparison with these previous studies more difficult, we feel that diaphragm ultrasound has become a well-studied modality, with described reproducibility, applied noninvasively and relatively easily learned [43]. Previous work has characterized the technical performance of diaphragm ultrasonography with thickness measurements being highly reproducible (mean \pm SD $2.4 \pm 0.8 \mathrm{~mm}$, repeatability coefficient $0.2 \mathrm{~mm}$, reproducibility coefficient $0.4 \mathrm{~mm}$ ), while thickening fraction was only moderately reproducible (median $11 \%$, IQR $3-17 \%$, repeatability coefficient $17 \%$, reproducibility coefficient $16 \%$ ) [43].

Sputum production and tenacity is a hallmark feature of CF; however, we did not assess changes in secretion characteristics during this study. Although the added humidity of HFNT could reduce secretion thickness, this should be an area of future investigation.

An important limitation was that patients were stabilized prior to study inclusion, as already mentioned. Importantly, however, we demonstrated that HFNT significantly improves breathing pattern in patients recovering from CF exacerbations and therefore holds promise that HFNT may confer benefit even in more acute and decompensated presentations.

\section{Conclusion}

No difference is observed in HFNT compared to NIV with respect to the diaphragmatic work per breath in CF patients stabilized after a clinical indication for ventilatory support but significantly reduces the respiratory rate and the work per minute. These preliminary data suggest that high-flow therapy may confer physiological benefits by decreasing ventilation needs and may constitute an interesting alternative or supplement to NIV.

\section{Additional file}

Additional file 1. Electronic supplementary material.

\section{Abbreviations}

COPD: chronic obstructive pulmonary disease; CF: cystic fibrosis; HFNT: highflow nasal therapy; ICU: intensive care unit; NIV: noninvasive ventilation; PEEP: positive end-expiratory pressure; PEEPi: intrinsic positive end-expiratory pressure; $\mathrm{PaCO}_{2}$ : partial pressure of arterial carbon dioxide; $\mathrm{PtCCO}_{2}$ : transcutaneous carbon dioxide; PTPdi: pressure time product of the diaphragm; TFdi: thickening fraction of the diaphragm.

\section{Authors' contributions}

MCS, NR, MD and LB contributed to study design, protocol implementation and manuscript preparation; BW and CC contributed to protocol implementation, research ethics approval and manuscript preparation; IT, TP, DLG, MR and FM contributed to protocol implementation and manuscript preparation; and ET and LB contributed to study oversight and design and manuscript preparation. All authors read and approved the final manuscript.

\section{Author details}

${ }^{1}$ Department of Anesthesia, University of Toronto, Toronto, Canada. ${ }^{2}$ Interdepartmental Division of Critical Care Medicine, University of Toronto, Toronto, Canada. ${ }^{3}$ Keenan Research Centre for Biomedical Science, Li Ka Shing Knowledge Institute, St. Michael's Hopsital, 209 Victoria Street, 4th Floor, Room 411, Toronto, ON M5B 1T8, Canada. ${ }^{4}$ Neurophysiologie Respiratoire Expérimentale et Clinique, Sorbonne Universités, Paris, France. ${ }^{5}$ Division of Respiratory Diseases and Tuberculosis, Department of Medicine, Faculty of Medicine Siriraj Hospital, Bangkok, Thailand. ${ }^{6}$ Division of Respirology, St. Michael's Hospital, Toronto, Canada. ${ }^{7}$ Department of Anesthesiology and Intensive Care Medicine, Catholic University of the Sacred Heart, Fondazione "Policlinico Universitario A. Gemelli", Rome, Italy. ${ }^{8}$ Department of Medicine, Faculty of Medicine Ramathibodi Hospital, Mahidol University, Bangkok, Thailand. ${ }^{9}$ Department of Anaesthesia and Intensive Care, University of Foggia, Foggia, Italy. ${ }^{10}$ Department of Medicine and Surgery, Research Center on Public Health, University of Milano-Bicocca, Monza, Italy.

\section{Acknowledgements}

This study was supported by a grant from the Canadian Cystic Fibrosis Foundation, and equipment for the study was provided by Fisher \& Paykel. These data were presented in abstract from at the 2017 European Society of Intensive Care Medicine Meeting, Vienna, Austria, October 2017.

\section{Competing interests}

Fisher Paykel provided equipment and a research grant to facilitate the study.

Availability of data and materials

The datasets supporting the conclusions of this article are included within the article (and its Additional file 1).

\section{Consent for publication \\ Not applicable.}

\section{Ethics approval and consent to participate}

The study was approved by the Research Ethics Board at St. Michael's Hospital.

Informed consent

Informed consent was obtained from patients prior to enrollment.

\section{Publisher's Note}

Springer Nature remains neutral with regard to jurisdictional claims in published maps and institutional affiliations.

Received: 28 April 2018 Accepted: 30 August 2018

Published online: 05 September 2018 


\section{References}

1. Davies JC, Alton EWFW, Bush A. Cystic fibrosis. BMJ. 2007;335:1255-9.

2. Fauroux B. Why, when and how to propose noninvasive ventilation in cystic fibrosis? Minerva Anestesiol. 2011;77:1108-14.

3. Fauroux B, Burgel P-R, Boelle P-Y, Cracowski C, Murris-Espin M, NoveJosserand $R$, et al. Practice of noninvasive ventilation for cystic fibrosis: a nationwide survey in France. Respir Care. 2008:53:1482-9.

4. Young AC, Wilson JW, Kotsimbos TC, Naughton MT. Randomised placebo controlled trial of non-invasive ventilation for hypercapnia in cystic fibrosis. Thorax. 2008;63:72-7.

5. Hart N, Polkey MI, Clément A, Boulé M, Moxham J, Lofaso F, et al. Changes in pulmonary mechanics with increasing disease severity in children and young adults with cystic fibrosis. Am J Respir Crit Care Med. 2002;166:61-6.

6. Demoule A, Chevret S, Carlucci A, Kouatchet A, Jaber S, Meziani F, et al. Changing use of noninvasive ventilation in critically ill patients: trends over 15 years in francophone countries. Intensive Care Med. 2016;42:82-92.

7. Keenan SP, Sinuff T, Cook DJ, Hill NS. Which patients with acute exacerbation of chronic obstructive pulmonary disease benefit from noninvasive positive-pressure ventilation? A systematic review of the literature. Ann Intern Med. 2003;138:861-70.

8. Pisani L, Fasano L, Corcione N, Comellini V, Musti MA, Brandao M, et al. Change in pulmonary mechanics and the effect on breathing pattern of high flow oxygen therapy in stable hypercapnic COPD. Thorax. 2017;72:373-5.

9. Fraser JF, Spooner AJ, Dunster KR, Anstey CM, Corley A. Nasal high flow oxygen therapy in patients with COPD reduces respiratory rate and tissue carbon dioxide while increasing tidal and end-expiratory lung volumes: a randomised crossover trial. Thorax. 2016:71:759-61.

10. Lepere V, Messika J, La Combe B, Ricard J-D. High-flow nasal cannula oxygen supply as treatment in hypercapnic respiratory failure. Am J Emerg Med. 2016;34:1914.e1-2.

11. Möller W, Celik G, Feng S, Bartenstein P, Meyer G, Oliver E, et al. Nasal high flow clears anatomical dead space in upper airway models. J Appl Physiol Bethesda Md. 1985;2015(118):1525-32.

12. Papazian L, Corley A, Hess D, Fraser JF, Frat J-P, Guitton C, et al. Use of high-flow nasal cannula oxygenation in ICU adults: a narrative review. Intensive Care Med. 2016:42:1336-49.

13. Frat J-P, Thille AW, Mercat A, Girault C, Ragot S, Perbet S, et al. High-flow oxygen through nasal cannula in acute hypoxemic respiratory failure. N Engl J Med. 2015;372:2185-96.

14. Stéphan F, Barrucand B, Petit P, Rézaiguia-Delclaux S, Médard A, Delannoy $B$, et al. High-flow nasal oxygen vs noninvasive positive airway pressure in hypoxemic patients after cardiothoracic surgery: a randomized clinical trial. JAMA. 2015;313:2331-9.

15. Hernández G, Vaquero C, González P, Subira C, Frutos-Vivar F, Rialp G, et al. Effect of postextubation high-flow nasal cannula vs conventional oxygen therapy on reintubation in low-risk patients: a randomized clinical trial. JAMA. 2016:315:1354-61.

16. Hernández G, Vaquero C, Colinas L, Cuena R, González P, Canabal A, et al. Effect of postextubation high-flow nasal cannula vs noninvasive ventilation on reintubation and postextubation respiratory failure in high-risk patients: a randomized clinical trial. JAMA. 2016;316:1565-74.

17. Bräunlich J, Köhler M, Wirtz H. Nasal highflow improves ventilation in patients with COPD. Int J Chron Obstruct Pulmon Dis. 2016;11:1077-85.

18. Rittayamai N, Tscheikuna J, Praphruetkit N, Kijpinyochai S. Use of high-flow nasal cannula for acute dyspnea and hypoxemia in the emergency department. Respir Care. 2015;60:1377-82.

19. Goligher EC, Slutsky AS. Not just oxygen? Mechanisms of benefit from high-flow nasal cannula in hypoxemic respiratory failure. Am J Respir Crit Care Med. 2017;195:1128-31.

20. Papa GFS, Pellegrino GM, Marco FD, Imeri G, Brochard L, Goligher E, et al. A review of the ultrasound assessment of diaphragmatic function in clinical practice. Respiration. 2016;91:403-11.

21. Moran F, Bradley JM, Piper AJ. Non-invasive ventilation for cystic fibrosis. Cochrane Database Syst Rev. 2017:2:CD002769.

22. Storre JH, Steurer B, Kabitz H-J, Dreher M, Windisch W. Transcutaneous $\mathrm{PcO} 2$ monitoring during initiation of noninvasive ventilation. Chest. 2007:132:1810-6.

23. Voscopoulos C, Brayanov J, Ladd D, Lalli M, Panasyuk A, Freeman J. Special article: evaluation of a novel noninvasive respiration monitor providing continuous measurement of minute ventilation in ambulatory subjects in a variety of clinical scenarios. Anesth Analg. 2013;117:91-100.

24. Vivier E, Mekontso Dessap A, Dimassi S, Vargas F, Lyazidi A, Thille AW, et al. Diaphragm ultrasonography to estimate the work of breathing during non-invasive ventilation. Intensive Care Med. 2012;38:796-803.

25. Umbrello M, Formenti P, Longhi D, Galimberti A, Piva I, Pezzi A, et al. Diaphragm ultrasound as indicator of respiratory effort in critically ill patients undergoing assisted mechanical ventilation: a pilot clinical study. Crit Care. 2015:19:161.

26. Matamis D, Soilemezi E, Tsagourias M, Akoumianaki E, Dimassi S, Boroli F, et al. Sonographic evaluation of the diaphragm in critically ill patients. Technique and clinical applications. Intensive Care Med. 2013;39:801-10.

27. Rittayamai N, Tscheikuna J, Rujiwit P. High-flow nasal cannula versus conventional oxygen therapy after endotracheal extubation: a randomized crossover physiologic study. Respir Care. 2014;59:485-90.

28. Dyspnea. Mechanisms, assessment, and management: a consensus statement. American Thoracic Society. Am J Respir Crit Care Med. 1999;159:321-40.

29. Goligher EC, Laghi F, Detsky ME, Farias P, Murray A, Brace D, et al. Measuring diaphragm thickness with ultrasound in mechanically ventilated patients: feasibility, reproducibility and validity. Intensive Care Med. 2015;41:642-9.

30. Rodriguez P, Lellouche F, Aboab J, Buisson CB, Brochard L. Transcutaneous arterial carbon dioxide pressure monitoring in critically ill adult patients. Intensive Care Med. 2006:32:309-12.

31. Goligher EC, Fan E, Herridge MS, Murray A, Vorona S, Brace D, et al. Evolution of diaphragm thickness during mechanical ventilation. Impact of inspiratory effort. Am J Respir Crit Care Med. 2015;192:1080-8.

32. Orde SR, Boon AJ, Firth DG, Villarraga HR, Sekiguchi H. Diaphragm assessment by two dimensional speckle tracking imaging in normal subjects. BMC Anesthesiol. 2016;16:43.

33. Delorme M, Bouchard P-A, Simon M, Simard S, Lellouche F. Effects of high-flow nasal cannula on the work of breathing in patients recovering from acute respiratory failure. Crit Care Med. 2017:45:1981-8.

34. Dassios TG, Doudounakis S, Dimitriou G. Maximum rate of pressure development and maximal relaxation rate of respiratory muscles in patients with cystic fibrosis. Respir Care. 2013;58:474-81.

35. Holland AE, Wilson JW, Kotsimbos TC, Naughton MT. Metabolic alkalosis contributes to acute hypercapnic respiratory failure in adult cystic fibrosis. Chest. 2003;124:490-3.

36. Al-Ghimlas F, Faughnan ME, Tullis E. Metabolic alkalosis in adults with stable cystic fibrosis. Open Respir Med J. 2012;6:59-62.

37. Mauri T, Turrini C, Eronia N, Grasselli G, Volta CA, Bellani G, et al. Physiologic effects of high-flow nasal cannula in acute hypoxemic respiratory failure. Am J Respir Crit Care Med. 2017;195:1207-15.

38. Mündel T, Feng S, Tatkov S, Schneider H. Mechanisms of nasal high flow on ventilation during wakefulness and sleep. J Appl Physiol. 2013:114:1058-65.

39. Blanch L, Bernabé F, Lucangelo U. Measurement of air trapping, intrinsic positive end-expiratory pressure, and dynamic hyperinflation in mechanically ventilated patients. Respir Care. 2005;50:110-24

40. Diehl J-L, Piquilloud L, Richard J-CM, Mancebo J, Mercat A. Effects of extracorporeal carbon dioxide removal on work of breathing in patients with chronic obstructive pulmonary disease. Intensive Care Med. 2016;42:951-2

41. Lenglet H, Sztrymf B, Leroy C, Brun P, Dreyfuss D, Ricard J-D. Humidified high flow nasal oxygen during respiratory failure in the emergency department: feasibility and efficacy. Respir Care. 2012;57:1873-8.

42. Fauroux B, Nicot F, Essouri S, Hart N, Clément A, Polkey Ml, et al. Setting of noninvasive pressure support in young patients with cystic fibrosis. Eur Respir J. 2004;24:624-30.

43. Dwyer TJ, Robbins L, Kelly P, Piper AJ, Bell SC, Bye PTP. Non-invasive ventilation used as an adjunct to airway clearance treatments improves lung function during an acute exacerbation of cystic fibrosis: a randomised trial. J Physiother. 2015:61:142-7.

44. Fraticelli AT, Lellouche F, L'her E, Taillé S, Mancebo J, Brochard L. Physiological effects of different interfaces during noninvasive ventilation for acute respiratory failure. Crit Care Med. 2009;37:939-45.

45. Mauri T, Alban L, Turrini C, Cambiaghi B, Carlesso E, Taccone P, et al. Optimum support by high-flow nasal cannula in acute hypoxemic respiratory failure: effects of increasing flow rates. Intensive Care Med. 2017:43:1453-63. 